\title{
An agro-pastoral household model for the rangelands of East Africa
}

\author{
P.K. Thornton ${ }^{\mathrm{a}, *}$, K.A. Galvin ${ }^{\mathrm{b}, \mathrm{c}}$, R.B. Boone ${ }^{\mathrm{b}}$ \\ anternational Livestock Research Institute (ILRI), PO Box 30709, Nairobi, Kenya \\ ${ }^{\mathrm{b}}$ Natural Resource Ecology Laboratory, Colorado State University, Fort Collins, CO 80523, USA \\ ${ }^{\mathrm{c}}$ Department of Anthropology, Colorado State University, Fort Collins, CO 80523, USA
}

Accepted 22 August 2001

\begin{abstract}
East Africa contains areas with some of the greatest large mammal biodiversity on the planet. These areas are key natural resources for the economic development of the region. They are also key areas for pastoralists who have co-existed with wildlife for millennia. Increasing populations, conflicts between wildlife and cattle, and the growth of agriculture, are all placing great pressure on these lands This paper describes the development of a pastoralist socio-economic model that is linked to the Savanna ecosystem model. In this way, options and scenarios could be investigated for their impacts not only on the ecosystem but also on pastoralist households and their welfare. The model, named PHEWS (Pastoral Household and Economic Welfare Simulator), tracks the flow of cash and dietary energy in pastoralist households using a simple set of rules. The model was calibrated for the Ngorongoro Conservation Area (NCA), northern Tanzania. The results of two population increase scenarios are presented. Model results indicate that all households in NCA depend to some degree on outside sources of calories, and that pastoralist welfare in NCA, even with small amounts of agriculture allowed, is under severe pressure at current human population levels. Strengths and weakness of the model are discussed, and next steps in its application identified. (C) 2002 Elsevier Science Ltd. All rights reserved.

Keywords: Agro-pastoralism; Savanna; Simulation; Dietary energy; Cash flow; Ngorongoro Conservation Area
\end{abstract}

* Corresponding author. Tel.: + 254-2-630-743; fax: + 254-2-631-499.

E-mail address: p.thornton@cgiar.org (P.K. Thornton). 


\section{Introduction}

A major challenge for the pastoral regions of East Africa is the establishment of a more appropriate and sustainable balance between food security and natural resource conservation. It is not easy to formulate and implement workable compromises between wildlife conservation and the people who live with wildlife. Conflicts tend to arise and deepen as human populations expand. A wide range of ecological, social, political and economic factors impinge on virtually all humanwildlife interactions, but the importance of these factors varies from one situation to another.

Historically, pastoralism and wildlife conservation must have been compatible in East Africa. But modernisation processes and changes in pastoral populations and land use have altered the patterns of interaction between pastoralists, wildlife and their jointly occupied ecosystems (Galvin et al., 2001). The recent past has seen a decline in economic welfare and chronic states of under-nutrition for pastoral populations (Galvin, 1992; Homewood, 1992). Alarming decreases in livestock and wildlife over the last two decades suggest that the carrying capacity of range land has declined, possibly because there has been progressive range-land degradation, resulting from excessive livestock densities and restricted livestock movements. Unfortunately, there are few data that conclusively show a decline in range production or that livestock densities are too high.

The Integrated Modeling and Assessment System (IMAS) project was a research effort designed to address some of the difficult issues associated with tradeoffs between different conservation policies. This project built on a large base of previous research in the region, and has involved many partners. IMAS is based upon an existing spatial-dynamic ecosystem model, the Savanna model (Coughenour, 1993; Ellis and Coughenour, 1998), which was originally developed for a pastoral ecosystem in northern Kenya. Savanna simulates plant growth responses to soil, weather, and herbivore foraging, energetic status, and population sizes of both wild and domestic herbivores. The research project included a component to develop and apply a socio-economics module that could be linked to Savanna, allowing different scenarios to be simulated and the interactions between livestock and wildlife predicted, in terms of spatial-dynamic competition for forage, disease transmission and effects, and impacts on household food security and cash flow. The IMAS project as a whole, including modelling work as well as field studies, was designed to quantify the impacts of land tenure, enterprise scale, and conservation policy on four objectives: pastoral welfare, livestock production, wildlife conservation, and ecosystem integrity.

The complexities of pastoralist-wildlife systems are such that an integrated approach has to be taken. Modelling provides a tool for quantifying the major processes and interactions involved. Modelling is also relatively objective; different stakeholders may have very different goals, but these goals can be set up as scenarios to be tested using the IMAS, and the likely impacts on the various system components can be visualised and assessed by all stakeholders. This can then be one input to discussions aimed at resolving conflicts. 
In this paper, we describe a simple rule-based household model that is linked to the Savanna ecosystem model, that can be used to assess certain aspects of household welfare and food security. The model has been calibrated for the Ngorongoro Conservation Area in Tanzania, and we describe some scenarios that have been run with the model. We conclude with a discussion of the strengths and weaknesses of the household model, and list further development and application work that is in progress. First, we provide a very brief overview of the ecosystem model to which the household model is linked.

\section{Brief overview of the Savanna model}

The Savanna model of Coughenour (1993) was originally developed for pastoral areas of northern Kenya. It has subsequently been adapted and applied in other areas of East Africa, the USA, and Australasia. Savanna simulates the processes in an ecosystem using a weekly time step. Ellis and Coughenour (1998) note that Savanna is unusual, or possibly unique, in that:

1. it couples an ecosystem-grazing system simulation with remotely sensed and other spatial databases within a GIS format;

2. at each time step it simulates changes in vegetation quantity, quality and distribution in response to climate and other drivers (such as fire), as well as removal by herbivores;

3. it simulates the spatial redistribution of herbivores in response to changes in vegetation quality and availability; and

4. it simulates the production and demographic responses of herbivores to changes in vegetation.

Savanna is a large and complex model, consisting of a number of component submodels (Boone and Coughenour, 2000). For example, the soil model in Savanna is used to model water and nutrient transfers. In the area of land being simulated, there may be many different soil types, and each soil type has its own set of properties for input to Savanna. Each soil is represented as being composed of three layers, the thickness of each being a model input. Water flow from one layer to the next is modelled using a Ritchie tipping bucket scheme (Ritchie, 1998). If the soil is saturated, water passes on to deep drainage. Herbs can use the water from the top two soil layers in Savanna, while woody plants can use water from all three layers.

In addition to the soils subcomponent, Savanna has modules to deal with weather modelling, light modelling, biomass allocation to plant parts, transpiration and net primary production, vegetation population dynamics, plant decomposition and nitrogen mineralisation, and animal energy balances and population dynamics. Savanna can model the movement of animals into and out of the study area. It calculates a habitat suitability index for each animal population at each time step, based on information such as elevation, plant cover and forage density. Animal populations are placed in the landscape at each time step based on this index. 
Animal densities may be constrained using force maps in Savanna, to take account of physical restrictions such as fences or high likelihood of disease, and distance to water maps (Boone and Coughenour, 2000).

The simulation tools in the IMAS itself consists of the Savanna model, a disease submodel to study important interactions between wildlife and livestock diseases (Howe et al., 1999), and the socio-economics submodel described later. Household and agricultural sites are also modelled in Savanna. Each household may have a certain amount of agricultural land associated with it. Households and their agricultural plots are located in the landscape according to the probability that each grid cell may contain households. In scenarios of population growth, households are added to the landscape on the basis of the density map.

\section{Development of the household model}

One of the first design criteria to be drawn up for the household model was that a simple rule-based approach would be used. One reason for this is that several of the pastoral systems have limited market integration, and a household economic approach is only of partial relevance in such systems. The rule-based framework developed, however, is flexible enough to be used for systems with much more market integration. An unpublished pastoral model, developed by M.B. Coughenour and D. Swift for Turkana in northern Kenya, was useful as a starting point. A second reason for a simple, rule-based approach is that the setting up of rules and parameterisation of the model to produce plausible behaviour is more easily achieved in situations of data paucity. A third factor that impinged on the decision to follow a rule-based approach was the recent building and testing of simple, topdown models that seem to offer substantial benefits with respect to the simplicity of the model processes and relatively short development cycle, while still providing useful information to the modeller and other users. Some work on simple dynamic land-use models was reported in Thornton and Jones (1997) with developments in Thornton and Jones (1998) and Jones and Thornton (1999), and a similar model was applied in a real-world situation, looking at intensification of agriculture in response to livestock disease control programmes in central Ethiopia, in Reid et al. (2001).

The general modelling approach taken was thus to use a small set of rules that govern the operation of the model, and then use the revealed characteristics of the model through simulations to adjust some of the key model parameters, so that reasonable and realistic (as far as we could judge) behaviour of the model is obtained. As a basic rule, we hypothesised that there is a quantity, $T$, of Tropical Livestock Units (TLUs, a measure of animal biomass) per person that characterises pastoral systems. This value $T$ is not known with much clarity, but we assume that it increases to levels at which the operator becomes a commercial beef rancher, and it decreases to the point where agro-pastoralism commences (and at zero it defines agriculture). The rules in the household model reflect the management decisions that are taken to aim at this target TLU per person, which may vary with wealth levels. If 
there are excess animals, these can be sold for cash. If there is a deficit, then animals can be purchased, if there are resources to do so.

We also hypothesised a hierarchy of goals at the household level. First, the household has to meet its food requirement. If there is a shortfall, then this is made up by recourse to various options, including the selling of an animal, if necessary. Second, the household is assumed to manage for $T$ in terms of investment and disinvestment decisions - these types of livestock purchases and sales are considered to be different to the meeting of household food requirements. Third, there is discretionary consumption. After the first two goals have been dealt with, with consequent impacts on the cash reserves (e.g. purchase of food), there may be a certain amount of cash left over for spending on various items.

The model, named PHEWS (Pastoral Household Economics and Welfare Simulator), currently consists of approximately 1700 lines of FORTRAN code, and is compiled along with the rest of the Savanna modelling system using version 4.0 of the Lahey Fortran 90 compiler (Lahey, 1997). The model currently treats three different household types, stratified in terms of wealth, which are taken to be representative of households within each stratum. In the model, wealth relates to the number of livestock each household has, and these three household types are characterised by different numbers of people. We use the term "household" to refer to an adult male decision maker, his (sometimes multiple) wives and their children, and other family members living within such a grouping (Galvin et al., 2001).

The model consists of a set of subroutines. The first of these is used to initialise the model. It calculates initial herd numbers by household type, and generally sets up the various arrays and parameters that are needed. The major data input files are read, and starting numbers of TLUs, Adult Equivalents (AE, a means to standardise household size based on the calorific requirements of particular age and sex groups in the household) and the target ratios are calculated and stored.

For each iteration of time in the model (usually one calendar month), a series of calculations is gone through for each household type. The controlling subroutine is called each iteration. It updates animal numbers, then updates the welfare ratios. If the particular month is a harvest month (specified in one of the input data files), then a subroutine is called to calculate yields for maize and other garden crops based on 5 months total rainfall. Cash flow is then updated that month, by adding in what is sold and subtracting what is bought, other than food. Household energy flow is then dealt with. Sources of dietary energy are milk, maize (own or bought), dead animals, the occasional stochastic slaughter, and finally gifts or relief. If maize is purchased, and if milk is sold, then the cash boxes are updated. If animals are sold or bought this iteration, then cash variables are updated. Each iteration, one record of output variables is written to the output files. If livestock numbers have changed in the model this iteration, through being sold or killed, then herd numbers are updated. Finally in each iteration, if spatial outputs are required (specified by the user), then these are written to the appropriate output files. Once the run is complete, and all iterations have been finished, a subroutine is called, which summarises various cumulative and global variables. Various components of PHEWS are described in more detail later. 


\subsection{Cash flow}

Cash flow for each household type each iteration involves simple additions and subtractions from a cash box. Sources of income and expenditures are listed in Table 1. Essentially, income is made up of any crop sales (the proportions of the crops sold for each household type are inputs demanded of the user), milk sales, wages and other sales plus gifts. Potential household expenditures are specified in terms of household goods each month, again specified as inputs by the user. If there is not enough cash to pay for all the projected expenditure, then household expenditure that iteration is pro rated if there is cash to meet at least $50 \%$ of projected expenditure. If there is less than this amount of cash in the household, then household expenditure that month is deferred, except expenditure on tea and sugar, which are paid for in cash, if there is enough, or assumed given as a gift to the household if there is not.

\subsection{Energy flow}

Energy flow in PHEWS is treated in a hierarchical fashion (Fig. 1). Household energy requirements are calculated for the current iteration; these depend on the number of people in the household, the age-sex ratios, and the assumed calorific requirement for each category. These energy requirements are met from various sources. First, the energy available from milk is calculated. This depends on the proportion of the cattle herd milking this iteration, and milk production per animal is calculated from a ramp function that relates milk yield to body condition. The calorific content of this amount of milk is then calculated. Some may be sold; this is subtracted from the milk energy variable. The rest is available for consumption,

Table 1

Cash flow in PHEWS ${ }^{\mathrm{a}}$

\begin{tabular}{|c|c|}
\hline Flow & How treated in PHEWS \\
\hline \multicolumn{2}{|l|}{ Cash in } \\
\hline Livestock sales & See Table 2 \\
\hline Crop sales & $\begin{array}{l}\text { Calculated as a household characteristic ( } \% \text { sold); the remainder is } \\
\text { consumed by the household }\end{array}$ \\
\hline Wages & From input file \\
\hline Milk sales & $\begin{array}{l}\text { Calculated a household characteristic ( } \% \text { sold }) \text {, the rest is consumed in } \\
\text { the household }\end{array}$ \\
\hline Other (gifts, crafts, etc) & From input file \\
\hline \multicolumn{2}{|l|}{ Cash out } \\
\hline Food purchases & $\begin{array}{l}\text { Calculated from the food flow (see Fig. 1). The balance of requirements } \\
\text { is purchased if cash is available }\end{array}$ \\
\hline Household goods & From input file \\
\hline Livestock purchases & See Table 2 \\
\hline Other payments out & From input file, plus crop inputs \\
\hline
\end{tabular}

\footnotetext{
a PHEWS, Pastoral Household and Economic Welfare Simulator.
} 


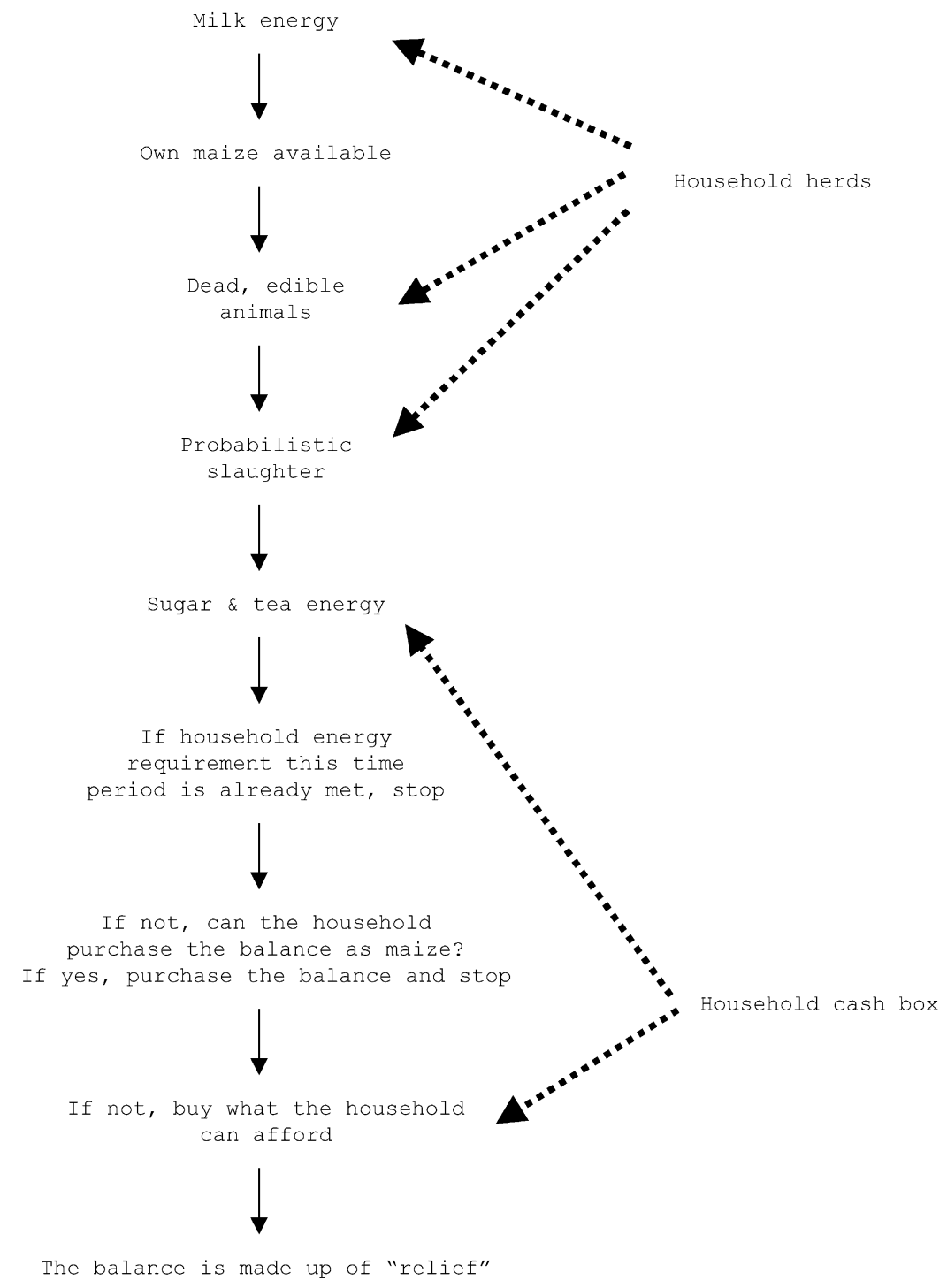

Fig. 1. The basic dietary energy flow hierarchy in Pastoral Household Economic Welfare Simulator (PHEWS).

although a ceiling is placed on the amount that can be consumed by the household in any one iteration.

Energy available from the household's own maize is then calculated for this iteration. At harvest, the total amount of maize harvested is stored in an array that makes the maize available over a 4-month period from the harvest date, but in decreasing amounts. The amount of "other" crops available to be sold is treated in similar fashion. 
The next source of dietary energy is from animals that starve or die from diseases that do not preclude their being eaten. Meat energy is calculated from the number of dying animals in each iteration, modified by the proportion that cannot be eaten because of the nature of the disease. The household also has access to meat energy through slaughtering an animal for ceremonial or festive occasions. This is controlled though a probability input to the model. As for milk, a ceiling is placed on meat calories (12\% of total calories consumed) in each household for each iteration.

Energy from sugar and tea is then taken into account, in relation to monthly input data. The total energy from milk, home-produced maize, meat and tea and sugar is then summed, and compared with the household's requirement. If the total is less, then the household attempts to buy maize to cover the deficit. This amount of maize (to exactly cover the shortfall) is purchased if the household has sufficient cash reserves. If the household does not have sufficient cash to purchase what is required, then as much maize as can be paid for is purchased, and any remaining shortfall is covered through an open-ended box that can be termed "gifts or relief (food aid)". In the rare cases where a household requires relief calories in any iteration and there may be some milk energy left over (after reaching the household's ceiling and selling the proportion allowed by the input data), then milk energy for that iteration can be increased up to a maximum of $50 \%$ of the household's requirement.

\subsection{Livestock trading}

Livestock purchases and sales are simulated using a simple matrix approach that specifies particular courses of action depending on the values of the two ratios. We define the following:

TTLU $=$ the target TLU per Adult Equivalent in the household.

$\operatorname{ATLU}_{t}=$ the actual TLU per Adult Equivalent at time $t$.

$\mathrm{TCL}=$ the target cash income per Adult Equivalent per month.

$\mathrm{ACL}_{t}=$ the actual cash income per month at time $t$.

The ratios $\mathrm{ATLU}_{t} / \mathrm{TTLU}$ and $\mathrm{ACL}_{t} / \mathrm{TCL}$ define indices of the severity of the livestock and cash problems facing the household. An idealised decision matrix is shown in Table 2. A major activity in calibrating PHEWS for a particular site is to adjust the ratio limits so that simulated livestock sales accord with such survey data as exist concerning livestock sales and purchases. This is discussed further later.

\subsection{Linkages to the Savanna model}

PHEWS is integrated with Savanna in terms of a set of major feedbacks. An example of one such feedback is what happens if an animal is sold. Savanna keeps track of all animal herds, in terms of both size and composition (age-sex ratios). 
Table 2

Idealised livestock trading matrix $(\mathrm{SR}=\text { small ruminant, } \mathrm{LR}=\text { large ruminant })^{\mathrm{a}}$

\begin{tabular}{|c|c|c|c|c|c|}
\hline & \multicolumn{5}{|c|}{$\operatorname{ATLU}_{t} / \mathrm{TTLU}$} \\
\hline & & $>1$ & $=1$ & $<1$ & $<<1$ \\
\hline \multirow[t]{4}{*}{$\mathrm{ACL}_{t} / \mathrm{TCL}$} & $>1$ & Buy SR & Buy SR & Buy LR & Buy LR \\
\hline & $=1$ & 0 & 0 & Buy SR & Buy SR \\
\hline & $<1$ & Sell SR & Sell SR & Sell SR & Sell SR \\
\hline & $<<1$ & Sell LR & Sell LR & Sell LR, SR & Sell LR, SR \\
\hline
\end{tabular}

a TTLU, the target tropical livestock units (TLU) per Adult Equivalent in the household; ATLU, the actual (at time t) TLU per Adult Equivalent; TCL, the target cash income per Adult Equivalent per month; $\mathrm{ACL}_{\mathrm{t}}$, the actual (at time $t$ ) cash income per month.

PHEWS operates on the basis of household herd sizes. Thus at the start of each iteration, PHEWS recalculates the herd size of livestock for each household type, a calculation that has to be done each iteration, as animals will have died and been born since the previous iteration. If during that iteration in PHEWS, an animal is sold or purchased, then adjustments need to be made to the number of animals and the herd composition. At the end of each iteration in PHEWS, household herd numbers and composition are totalled and aggregated, and appropriate adjustments are made to Savanna's variable arrays to reflect any changes.

\subsection{Input and output files}

Control of whether PHEWS is run or not resides in one of the standard Savanna input files (Table 3). This file controls a number of important parameters that describe a particular simulation run, including the length of simulation, the year and month to start, and various flags that specify the type of output produced. PHEWS generates a variety of output files, detailing cash flows, energy flows, and general household indicators.

Savanna itself (with or without PHEWS attached) can be run in various ways. One way is by using the Savanna Modelling System (SMS). The SMS was originally developed (Coughenour, 1993) to provide a user-friendly environment for editing input files to set up a scenario, running the scenario with Savanna, and then looking at the outputs of the scenario either spatially or temporally. PHEWS is now integrated with the SMS on the output side, so that model results from the socioeconomics of the system can be graphed and mapped as required by the user, in exactly the same way as for the ecological outputs.

For temporal outputs, a wide range of variables from PHEWS can be graphed by household type in SMS. If comparisons are required for one variable between household types, then cutting-and-pasting with a suitable text editor and importation of these ASCII output files into a software package such as Excel for subsequent graphing is straightforward. An attractive feature of the SMS is the ability to map outputs spatially and assess how spatial outputs change over time. A set of socio-economic outputs from PHEWS has been defined, and these are output to a 
Table 3

Input and output files for PHEWS

\begin{tabular}{|c|c|c|}
\hline File & Variables & Input or output \\
\hline SIMCON.PRM & Simulation control parameters & Savanna input file \\
\hline AGRIC.PRM & $\begin{array}{l}\text { Household sizes, agricultural holdings, population } \\
\text { growth rate }\end{array}$ & Savanna input file \\
\hline ECMOD.DAT & $\begin{array}{l}\text { Human and livestock age-sex ratios } \\
\text { Costs and prices } \\
\text { Income and expenditure data by household type } \\
\text { Livestock purchasing matrices }\end{array}$ & PHEWS input \\
\hline $\mathrm{DIETP} / \mathrm{M} / \mathrm{R}$ & $\begin{array}{l}\text { Household energy requirements, kcal } \\
\text { Proportion in diet of milk, maize, meat, sugar, } \\
\text { purchased maize and relief }\end{array}$ & Temporal output \\
\hline $\mathrm{HOUSP} / \mathrm{M} / \mathrm{R}$ & $\begin{array}{l}\text { Cash reserves, Tz Sh } \\
\text { Own maize and other crops available, } \mathrm{kg} \\
\text { TLU welfare and cash welfare ratio } \\
\text { Actual TLUs and Adult Equivalents }\end{array}$ & Temporal output \\
\hline CASHP/M/R & $\begin{array}{l}\text { Cash reserves, Tz Sh } \\
\text { Net income, Tz Sh } \\
\text { Crop, milk, livestock sales, Tz Sh } \\
\text { Household expenditures on tea, livestock purchases, } \\
\text { maize expenditure, Tz Sh }\end{array}$ & Temporal output \\
\hline ANIMP/M/R & $\begin{array}{l}\text { Cattle number, } \% \text { female, } \% \text { adult, in household herd } \\
\text { Goat number, } \% \text { female, } \% \text { adult in herd in household } \\
\text { herd } \\
\text { Sheep number, } \% \text { female, } \% \text { adult in household herd }\end{array}$ & Temporal output \\
\hline SEM_SUM.OUT & $\begin{array}{l}\text { Summary statistics at the end of each run detailing } \\
\text { cash and welfare levels for each household type }\end{array}$ & Final output \\
\hline IMAGE4 & $\begin{array}{l}\text { Household density, number } / \mathrm{km}^{2} \times 100 \\
\text { Agriculture, ha } / \mathrm{km}^{2} \times 10 \\
\text { Net income, Tz Sh } / 1000 \\
\text { Diet relief, \% } \\
\text { Household maize availability, } \mathrm{kg} / \mathrm{km}^{2} \\
\text { TLU per Adult Equivalent, number } \times 10 \\
\text { Household's own food availability, \% } \\
\text { Cash box, Tz Sh/1000 } \\
\text { Human population density, number } / \mathrm{km}^{2}\end{array}$ & Spatial and temporal output \\
\hline
\end{tabular}

a PHEWS, Pastoral Household and Economic Welfare Simulator; TLU, tropical livestock units.

mapping file that can then be accessed by SMS for mapping. Input and output files are summarised in Table 3.

\section{Model calibration for Ngorongoro Conservation Area, Tanzania}

The landscape of the Ngorongoro Conservation Area (NCA), Tanzania, encompasses highlands, forests, and grassy plains. Central to the area is the Ngorongoro Crater, renowned for its rich wildlife and spectacular scenery. The short grass plains of the NCA are the wet-season grazing grounds for many of the Serengeti's 
migratory herds of wildebeest, gazelle, and zebra. The highlands provide important habitat for rhinoceros, elephant, and buffalo. Prior to 1960, the Maasai had free access to the Conservation Area and to the adjacent Serengeti plains. In 1960, they were evicted from the Serengeti, and, in 1974, they were evicted from the Ngorongoro Crater. By 1995, some 42,000 Maasai lived in the Conservation Area, where they continued to graze cattle in non-restricted areas and to farm (Kijazi et al., 1997). The Maasai population remains largely impoverished, with most households earning less than $\$ 10$ a month.

The status of wildlife in the Ngorongoro Conservation Area is mixed. The population of black rhinoceros, the most threatened large mammal there, declined from more than 100 in the 1960s to 12 in 1995 and is on the verge of extinction (Moehlman et al., 1997). Other animal species listed as threatened or endangered by the World Conservation Union include the wild dog, the African elephant, and the cheetah. On the other hand, the wildebeest population, as well as that of other large herbivores, remains healthy. There are currently some 900,000 wildebeest in the Serengeti migratory herd, up from 240,000 in 1960. About one-third to one-half of these migrate into the Ngorongoro Conservation Area. The wildebeest increase followed the eradication of rinderpest, a disease fatal to wildebeest and cattle. The wildebeest population competes with other wildlife species and cattle for grazing land.

One of the major changes underway in the Ngorongoro ecosystem is the conversion of rangeland to farmland. In 1992, a ban on cultivation was temporarily lifted. As a result, within 3 years, $85 \%$ of Maasai were cultivating small plots of land. Cultivation was adopted as a means of maintaining their cattle and pastoral way of life. Others in the area have also taken advantage of the change in policy. Increasing areas of land are coming under cultivation. The use of Savanna and PHEWS could help to assess what the impacts of such changes might be. Such information could then be used by the Ngorongoro Conservation Area Authority, pastoral development groups, and local and regional wildlife conservation groups, in the quest to assess tradeoffs between wildlife, livestock and pastoralist wellbeing.

To calibrate PHEWS for NCA, various sources of data were available. These included previous studies and surveys in NCA itself (Homewood et al., 1987; Homewood and Rodgers, 1991; Thompson, 1997; NCAA, 1999; Galvin, 1994, 1995, 1997, 1998; Galvin et al., 1994, 1999; Magennis and Galvin, 2000), previous studies and surveys of pastoralism in areas of northern Tanzania, southern Kenya and elsewhere (Bekure et al., 1991; Dahl and Hjort, 1976), and studies and surveys carried out in NCA as part of the current research project (Smith, 1999; Lynn, 2000).

Calibration of the household model was to be done using the identical Savanna inputs that produced the "control" run of Boone and Coughenour (2000)-i.e. a baseline run that could be used as a benchmark against which to judge other scenarios. For NCA, Savanna has 17 herds of animals defined. Of these, three are of direct importance to the welfare of pastoralists: cattle, sheep and goats. Recent data (NCAA, 1999) indicate that human population growth in NCA has been highly volatile, but from 1970 onwards has been of the order of $8 \%$ per year overall. We estimated the population for 2000 as 46,600 , based on a linear regression of recent trends, and this number is taken as the baseline population figure for the control run. 
The proportion of poor, medium and rich households in NCA was estimated as 0.35, 0.40 and 0.25, respectively (McCabe et al., 1997b, p. 291; Homewood, 1992, p. 70; Potkanski, 1997). An issue of some uncertainty is the size of households (as defined earlier). The data of Smith (1999) indicate household sizes of about 14, 25 and 27 people per poor, medium and rich household, whereas other estimates are of the order of 10 persons or so (Bekure and Grandin, 1991; Kijasi et al., 1997). Our numbers are high because they reflect the actual number of people in the household at the time of the interview. We assume that the other published estimates relate to household size based on a man, his wives and their children only. For the control run, we assumed household sizes of 10,17 and 19 persons per household, giving a weighted average of 15 persons per household. Given this average household size, this suggests a total of 2991 households in NCA for the control run.

In terms of the herd sizes for the three household types, Boone and Coughenour (2000) used totals of 116,000 cattle and 193,000 sheep and goats in NCA (data from Kijazi et al., 1997), goats outnumbering sheep by an estimated ratio of 3 to 2 . To divide up the total cattle and smallstock population per household, we inferred household herd sizes from ratios found during field work (Smith, 1999), although some adjustments had to be made to preserve total herd numbers in relation to household numbers. In PHEWS, total livestock numbers are the driving force for household herd sizes. If human population increases are imposed on NCA, then household sizes remain the same; the number of households increases; and household livestock herds of cattle, sheep and goats will decrease, since the same numbers of animals must go round more households. It is thus important to get the initial balances right between households and herd sizes. Characteristics of the three household types for the control run are shown in Table 4, together with an indication of the source of the data.

There were some input data for which there are essentially no sources of information. These then became critical variables for calibrating the model, and they included the household TLU and cash income targets, and the livestock trading matrices by household wealth category.

\subsection{The NCA control model}

Boone and Coughenour (2000) describe the control model, which attempts to model Ngorongoro as it is now. The control model included seven types of vegetation-palatable grass, palatable forbs, unpalatable herbs, palatable shrubs, unpalatable shrubs, evergreen trees, and deciduous woods. The changes in plants are modelled for a 15-year period, from 1973 to 1988. The control model simulates seasonal changes in total biomass, in response to the wet and dry seasons. Particularly dry periods, such as the late 1970s, yield less biomass than wetter periods, such as the early 1980s. Livestock populations change each year, as animals in the 17 herds die and are born, and over the long term, as dry and wet periods are experienced in NCA. In the control model, populations for migratory animals are set as a constant. The proportion of animals in NCA changes from month to month, but the total does not. 
Table 4

Characteristics of household types used for the control run in $\mathrm{NCA}^{\mathrm{a}}$

\begin{tabular}{|c|c|c|c|c|c|}
\hline & $\begin{array}{l}\text { Poor } \\
\text { households }\end{array}$ & $\begin{array}{l}\text { Medium } \\
\text { households }\end{array}$ & $\begin{array}{l}\text { Rich } \\
\text { households }\end{array}$ & $\begin{array}{l}\text { Sum or } \\
\text { weighted } \\
\text { mean }\end{array}$ & Source \\
\hline $\begin{array}{l}\text { Proportion of households } \\
\text { in NCA }\end{array}$ & 0.35 & 0.40 & 0.25 & - & $\begin{array}{l}\text { Homewood (1992); } \\
\text { Potkanski (1997); } \\
\text { McCabe et al. (1997b) }\end{array}$ \\
\hline Number of households & 1047 & 1196 & 748 & 2991 & $\begin{array}{l}\text { NCAA (1999); } \\
\text { Smith (1999) }\end{array}$ \\
\hline $\begin{array}{l}\text { Cultivated land per } \\
\text { household (ha) }\end{array}$ & 0.67 & 0.89 & 1.42 & 0.95 & $\begin{array}{l}\text { Smith (1999); } \\
\text { McCabe et al. (1997a) }\end{array}$ \\
\hline $\begin{array}{l}\text { Total land area } \\
\text { cultivated (ha) }\end{array}$ & 701 & 1064 & 1062 & 2827 & Derived \\
\hline People per household & 12 & 17 & 19 & 15.0 & $\begin{array}{l}\text { NCAA (1999); } \\
\text { Smith (1999) }\end{array}$ \\
\hline Cattle per household & 11 & 31 & 90 & 39 & $\begin{array}{l}\text { Smith (1999); } \\
\text { estimated and derived }\end{array}$ \\
\hline Smallstock per household & 18 & 45 & 160 & 64 & $\begin{array}{l}\text { Smith (1999); } \\
\text { estimated and derived }\end{array}$ \\
\hline Total cattle & 11,517 & 37,076 & 67,407 & 116,000 & Kijazi et al. (1997) \\
\hline Total smallstock & 18,846 & 53,820 & 120,334 & 193,000 & Kijazi et al. (1997) \\
\hline
\end{tabular}

a NCA, Ngorongoro Conservation Area.

Ecologically, the outputs of the control model are quite stable: animal populations rise and fall annually and in response to longer-term weather patterns of belowaverage and above-average rainfall, but basically the system is relatively stable. For calibrating PHEWS, the object was to end up with similar stability in terms of household welfare and household herd numbers. The control run was thus undertaken with no population increase imposed.

Summary results for the NCA control run are tabulated in Table 5. The first six rows of the table show the total percentage makeup of diet for the three household types. Total milk consumed refers to the milk that is produced by the household's own herd. The data of Galvin (1994) and others (e.g. Homewood, 1992) show clearly that the diets of the Maasai in NCA do not vary much depending on household wealth. Assuming that gifts/relief (the portion of the diet that cannot be produced by the household from animals or crops, and that cannot be bought with cash) are mostly in milk (through the loan of milking stock), then the dietary figures from the control run indicate that NCA diets are made up of about $12 \%$ meat, $29 \%$ milk, and $56 \%$ grain, which accords well with the approximate 10:30:60 proportions for meat, milk and grain that other researchers have found (Nestel, 1985; Galvin, 1992; Homewood, 1992). A major indicator of household welfare is the percentage of gifts or relief. As might be expected, this changes sharply, depending on household wealth, from $13 \%$ of all dietary energy in poor households to zero for rich households. The problems that poor and medium households have are not surprising, given that these households have 1.07 and 1.65 TLUs per AE, on average. Even 
Table 5

Summary output for the control run over 15 years for the three household types ${ }^{\mathrm{a}}$

\begin{tabular}{lcrr}
\hline & Poor & Medium & Rich \\
\hline Total milk consumed (\% in diet) & 13.1 & 20.1 & 29.0 \\
Total own grain consumed (\% in diet) & 16.2 & 12.5 & 17.1 \\
Total meat consumed (\% in diet) & 11.8 & 11.9 & 11.5 \\
Total other (including sugar) (\% in diet) & 2.9 & 3.0 & 2.9 \\
Total bought grain consumed (\% in diet) & 42.5 & 44.1 & 39.6 \\
Total gifts/relief (\% in diet) & 13.4 & 8.4 & 0.0 \\
Total income from selling (Tz Sh, 000) & 498 & 686 & 2,826 \\
Cash used to buy food (Tz Sh, 000) & 1,098 & 1,951 & 2,108 \\
Average cashbox per month (Tz Sh) & 9,504 & 11,131 & 132,453 \\
Cashbox sd per month (Tz Sh) & 7,389 & 44.5 & 57,862 \\
Own food available (\%) & 41.1 & 1.65 & 4.40 \\
Average TLUs per Adult Equivalent & 1.07 & & 4.6 \\
\hline
\end{tabular}

a One US dollar equals about 800 Tanzanian Shillings (Tz Sh); TLU, tropical livestock units.

rich households have only 4.40 TLUs per AE, which is well below the theoretical threshold of 6-8 necessary for sustainable pastoralism (Dahl and Hjort, 1976; Galvin et al., 2001).

The need for poor households to receive gifts or relief is highly seasonal, as might be expected. Fig. 2 shows the average monthly relief figures for poor and medium households, and indicates that such households are clearly at serious risk of food insecurity during certain months, when the household's own resources can provide $60 \%$ or less of the energy requirements of the household members. Interestingly, there is an interaction between the time when households are most affected and household type. Poor households are, on average, particularly badly affected in December, January and February, while medium households are more affected in August, November and December. Medium households have larger herds and more area in crops compared with poor households, but they have more people than poor households (about 12 AEs compared with seven) and thus greatly increased monthly calorific requirements.

The results in Table 5 also highlight differences in income and cash used to buy food by household type (these are totals over the 15 years of the simulation run). The average size of the cash box per month is shown in row nine. The standard deviation of these figures by household type shows great variability; for poor and medium households alike, the $\mathrm{CV}$ is close to $100 \%$, again underlining the vulnerability of such households to cash shortages and thus to food shortages as well. Again, as might be expected, the results show that the richer the household, the greater the percentage of food available from the household's own resources, although even rich households are dependent for $40 \%$ of their calories on outside sources.

These results apply in a reasonably steady-state situation. Assuming that the calorie transfers via gifts and relief are actually occurring, then the control run describes a reasonably stable situation. Fig. 3 shows the evolution of household herd 


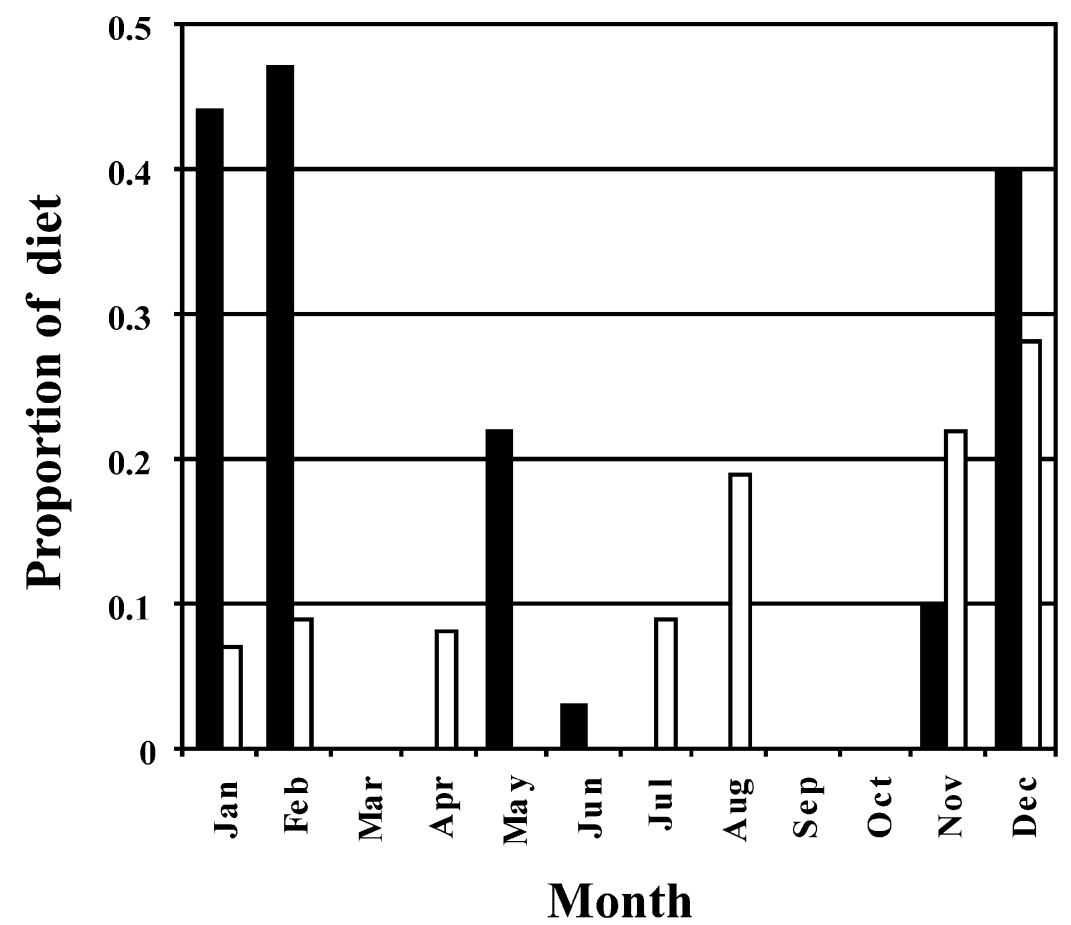

Door

$\square$ Medium

Fig. 2. Seasonality of the percentage of gift/relief calories in the diets of poor and medium households (control run, average of 15 years).

sizes for rich households. There is substantial seasonal variation, but the overall trends in livestock numbers per household are fairly flat. This is not surprising, given that total numbers are cyclical but stable (Boone and Coughenour, 2000) and that the number of households is constant. Similarly, if the two ratios, actual TLUs per $\mathrm{AE}$ and cash income per month per AE, or the two welfare ratios (these as a proportion of the household's desired numbers of TLUs and cash income), are plotted over time (data not shown), no trends are apparent for any of the household types. In a typical simulation year, poor households in the control run are selling two or three goats for cash; medium households are selling three goats and a steer for cash, while rich households are selling three or four steers during the year for cash.

In sum, the results from the control run for the household model show reasonable stability over a 15-year period, but sustainability of households and household welfare for the less well-off are still dependent on gifts and/or food relief. All households depend on "outside" food calories, which have to be purchased. The number of TLUs per AE for all household types is very low, and poorer households are very food- and cash-insecure. The control run clearly shows that pastoralist welfare in 


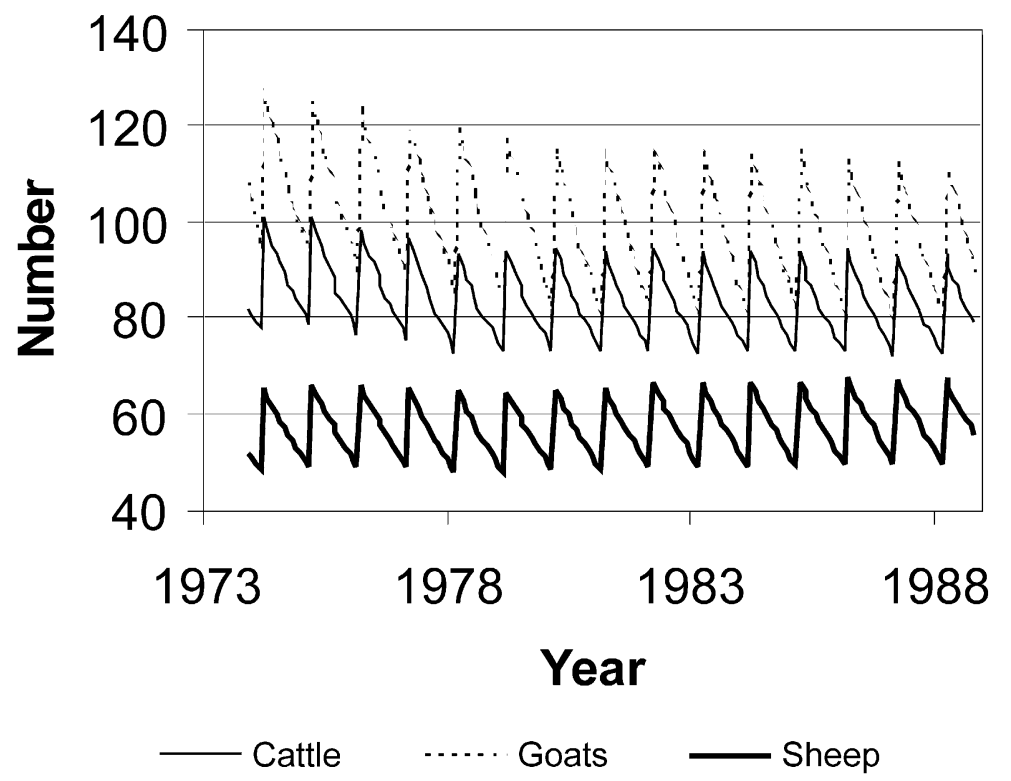

Fig. 3. Evolution of herd numbers for rich households, control run over 15 years.

NCA, even with small amounts of agriculture allowed, is not internally sustainable at current human population levels.

\subsection{Population growth rates of 3 and $6 \%$ per year}

As an example of some of the experimentation that has been carried out with PHEWS, we show the results of two scenarios involving human population growth over the next 15 years. These scenarios were identical to the control run, except that a human population growth rate of $3 \%$ per year was imposed, and then one of $6 \%$ per year. Table 6 shows three key summary indicators of household welfare for all household types, compared with the control run values. Fig. 4 shows the evolution of household herd sizes for poor households under the 3\% scenario. Livestock numbers are declining rapidly, as the number of households in the NCA is simulated to increase from 2990 to more than 4660 in the 15 -year simulation period. The change in household food security, as measured by the proportion of relief in the diet, is shown in Fig. 5 for both scenarios for poor households, in terms of the annual percentage of relief. A linear regression through these points shows an increase in relief of $0.34 \%$ per year for the $3 \%$ scenario and a $0.75 \%$ increase per year for the $6 \%$ scenario. The TLU ratio (actual to desired) declines over time for poor and medium households. Such households are caught in an increasing squeeze-fewer animals with which to feed the household, and fewer to sell for cash for grain, and no opportunities for increasing livestock numbers.

Fig. 6 shows the increase in human population density in NCA from the first month of the run to the last. Even with increasing areas of agriculture, as a result of 
Table 6

Summary output for scenarios with 3 and $6 \%$ population increase per year over 15 years for the three household types ${ }^{\mathrm{a}}$

\begin{tabular}{lccc}
\hline & Poor & Medium & Rich \\
\hline $3 \%$ Population increase & & & \\
Total gifts/relief $(\%$ in diet) & $15.7(+17)$ & $9.9(+18)$ & 0.1() \\
Own food available (\%) & $38.8(-6)$ & $41.5(-7)$ & $56.4(-2)$ \\
Average TLUs per Adult Equivalent & $0.86(-20)$ & $1.33(-19)$ & $3.55(-19)$ \\
& & & \\
6\% Population increase & $17.7(+32)$ & $11.7(+39)$ & 0.1() \\
Total gifts/relief $(\%$ in diet) & $36.7(-11)$ & $38.6(-13)$ & $54.3(-6)$ \\
Own food available (\%) & $0.68(-36)$ & $1.05(-37)$ & $2.8(-36)$ \\
Average TLUs per Adult Equivalent & & & \\
\hline
\end{tabular}

a Figures in parentheses show the percentage change from the control run (Table 5). TLU, tropical livestock units.

increasing numbers of households, the total area with a $6 \%$ increase per year is relatively small, and the impacts of a change from about 2800 ha (the current situation) to 6800 ha (after 15 years of $6 \%$ growth) of agriculture on wildlife numbers was shown to be very limited (Boone and Coughenour, 2000). It appears inevitable that any population growth from current numbers would adversely affect all households, but particularly the less well-off, whose food insecurity would do nothing but increase.

\section{Conclusions}

PHEWS appears to produce plausible behaviour in relation to the control run and to a wide range of scenarios inflicted on it (Galvin et al., 2000). This does not mean that the model is in any sense "valid" (this, strictly speaking, has yet to be determined), but it is a promising start. Indeed, there are no reasons why some highly specific fieldwork could not be designed to elicit information from pastoralists concerning their livestock trading decisions and household targets, but as yet this has not been done.

The preliminary results of scenario analysis suggest that in the NCA at current levels of population, food security and household welfare are of real concern. The poorer households depend for at least $10 \%$ of their calories on gifts and relief. They have little cash reserves in the household to tied them over periods of need. All households depend on outside sources of calories; even rich households obtain $40 \%$ of their diets from outside the household. Pastoralist welfare in NCA, even with small amounts of agriculture allowed, is under severe pressure at current human population levels. If realistic population growth rates are imposed, then the situation deteriorates markedly. The need for gifts and relief in all household types increases, and a squeeze occurs: fewer animals with which to feed the household, and fewer to sell for cash for grain, and no realistic opportunities for increasing livestock numbers. 


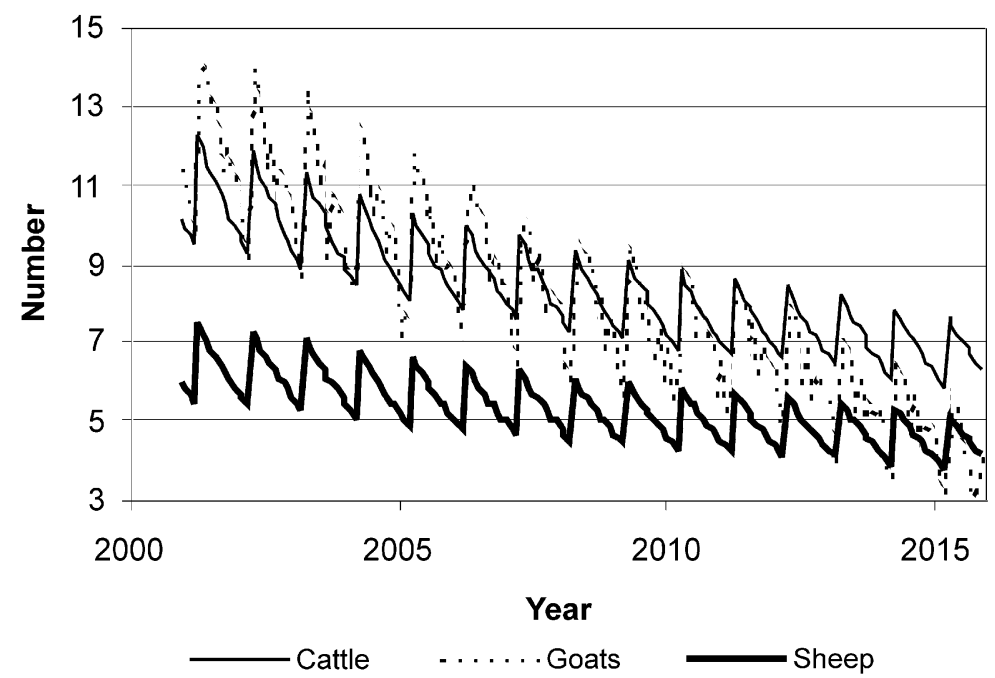

Fig. 4. Evolution of herd numbers for poor households with $3 \%$ annual human population growth.

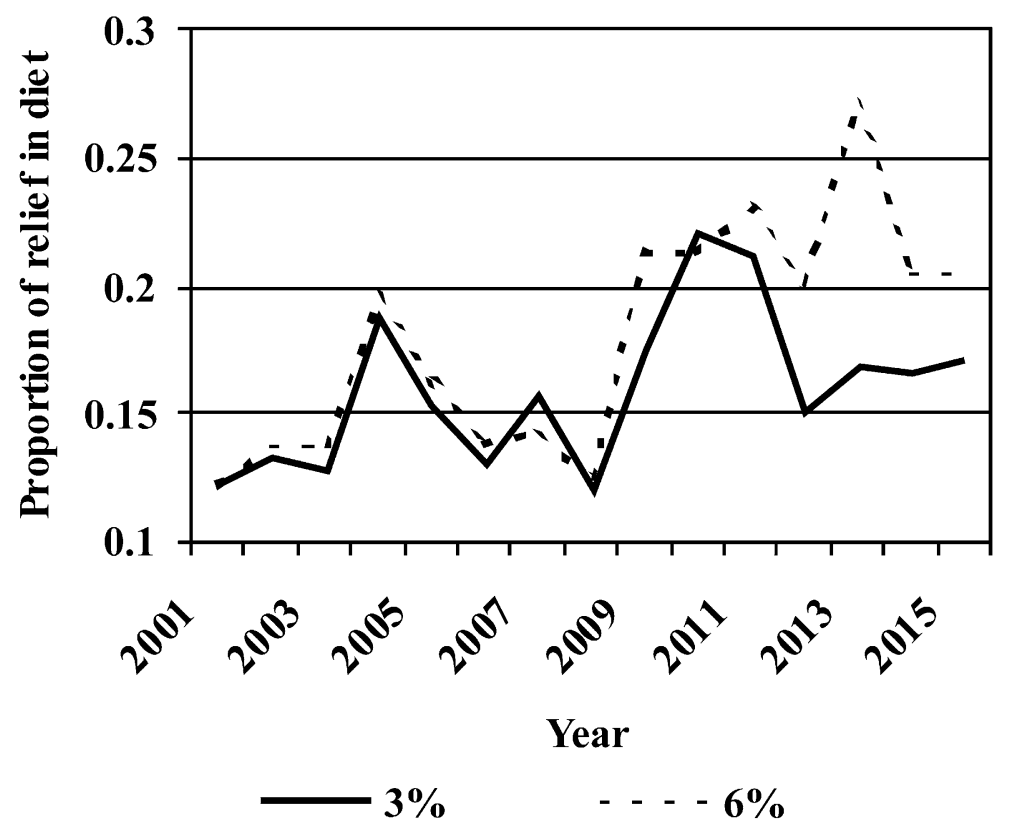

Fig. 5. Annual percentage of relief food in diets of poor households with 3 and $6 \%$ annual human population growth rates. 

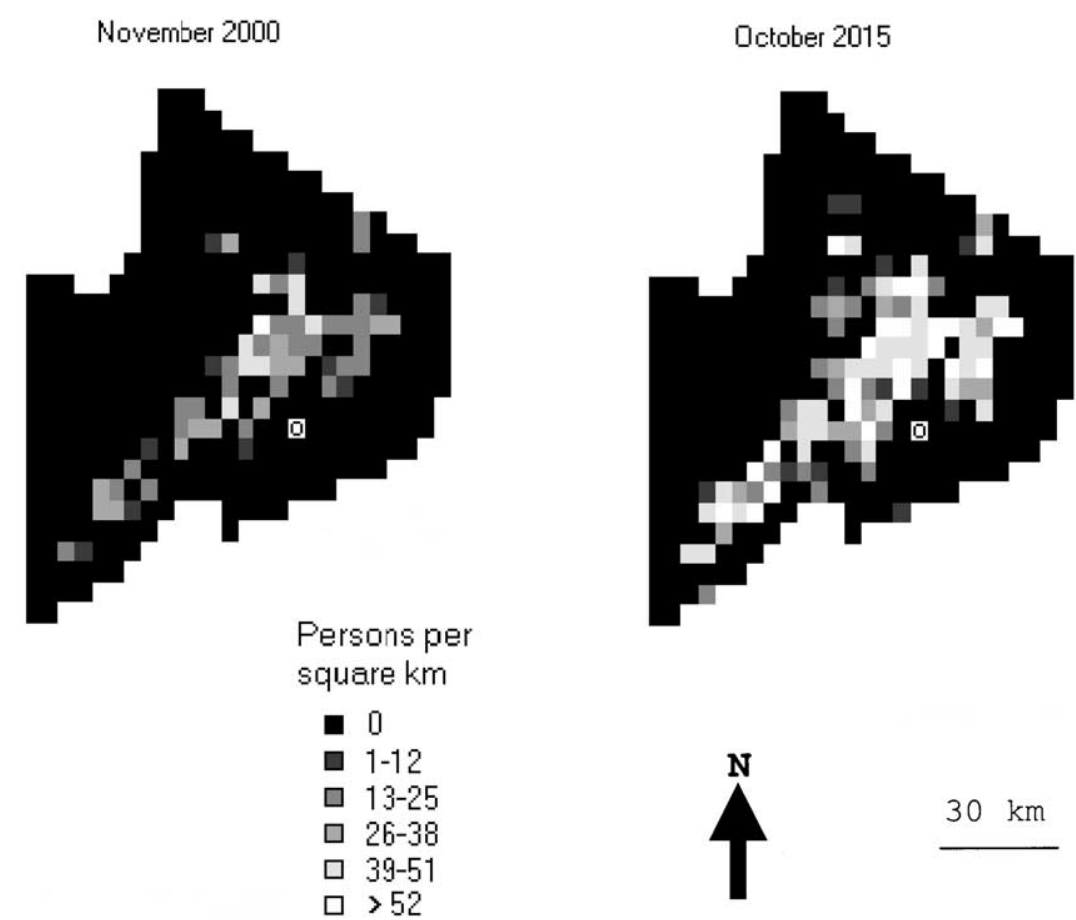

Fig. 6. Human population density in the Ngorongoro Conservation Area (persons per square $\mathrm{km}$ ) for the first and last month of the $6 \%$ annual human population growth rate scenario.

In terms of model performance, there is at least one area where some modification might usefully be made to PHEWS. The livestock trading matrices are an efficient device for assembling appropriate rules in the model, but the performance of this aspect of the model is very sensitive to the thresholds used. More work is required to make this aspect of PHEWS more robust. In addition, more field work is required to determine household behaviour in situations where herd productivity is changing over time. We know relatively little about the trade-offs that household engage in, between changing herd sizes and increasing animal off-take to improve cash flow.

PHEWS is currently being calibrated and applied to another site, the wildlife dispersal areas around Amboseli National Park in Kajiado District, southern Kenya. Modifications are having to be made to the model, to deal with the greater levels of market integration found there. Longer-term objectives of this work are (1) to combine the various modifications of PHEWS into a comprehensive socio-economics model that can eventually cover the spectrum from subsistence livestock keeping to commercial ranching systems, and (2) to develop and apply a regional socioeconomics model to problems of population growth, climate change and land-use impacts on the trade-offs involved between wildlife conservation, human activity, food security, and poverty alleviation.

There are good prospects for linking the Savanna and PHEWS models with other models that consider land-use change in a more explicit fashion, along the lines of 
Jones and Thornton (1999), for example. Such an assemblage of models could be used to address questions such as, how is the traditional strategy of pastoral mobility (mobility in grazing patterns, and mobility of livestock through stocksharing arrangements) modified within the constraints imposed by current land tenure arrangements (pre-subdivision group ranches, sub-divided group ranches), and how do changes in pastoral land use patterns (subdivision, sedentarization, etc.) affect human welfare, livestock production and the quantity and quality of human-wildlife interactions? Such questions address the trade-offs between the need to conserve wildlife and preserve or enhance the food security of a growing number of humans. Complementary interactions do exist under some conditions. The pressures on these systems are such that defining what these conditions are, and identifying how people and wildlife may be affected, have become extremely important questions that need to be answered sooner rather than later. Ecosystem models linked with simple household and land-use models appear to offer considerable potential for addressing these vital issues and for helping to inform the debate as to what is feasible and desirable for stakeholders with very different objectives.

\section{Acknowledgements}

We are grateful for research support provided by the Office of Agriculture and Food Security, Global Bureau, United States Agency for International Development, under Grant No. PCE-G-98-00036-00. The opinions expressed herein are those of the authors and do not necessarily reflect the views of the US Agency for International Development. This research was also supported in part by the US National Science Foundation (BNS-9100132 and SBR-9709762).

We thank Shauna Burnsilver, Mike Coughenour, Jim Ellis, Stacy Lynn, Ann Magennis, Terry McCabe, Robin Reid and Nicole Smith for important inputs to this work at various stages. All errors and omissions remain our responsibility, however.

\section{References}

Bekure, S., Grandin, B.E., 1991. Introduction. In: Bekure, S., de Leeuw, P.N., Grandin, B.E., Neate, P.J.H (Eds.), Maasai Herding: An Analysis of the Livestock Production System of Maasai Pastoralists in Eastern Kajiado District, Kenya (ILCA Systems Study Number 4). International Livestock Centre for Africa, Addis Ababa, Ethiopia, pp. 1-5.

Bekure, S., de Leeuw, P.N., Grandin, B.E., Neate, P.J.H., 1991. Maasai Herding: An Analysis of the Livestock Production System of Maasai Pastoralists in Eastern Kajiado District, Kenya (ILCA Systems Study Number 4). International Livestock Centre for Africa, Addis Ababa, Ethiopia.

Boone, R.B., Coughenour, M.B., 2000. Integrated Management and Assessment System: Balancing Food Security, Conservation and Ecosystem Integrity. Using Savanna and SavView in ecosystem modelling. NREL, CSU, Fort Collins, CO.

Coughenour, M.B., 1993. Savanna-A Spatial Ecosystem Model. Model Description and User Guide. NREL, Colorado State University, Fort Collins, CO. 
Dahl, G., Hjort, A., 1976. Having Herds. Pastoral Herd Growth and Household Economy (Stockholm Studies in Social Anthropology No. 2). University of Stockholm, Stockholm, Sweden.

Ellis, J.E., Coughenour, M.B., 1998. The Savanna integrated modelling system: an integrated remote sensing, GIS and spatial simulation modelling approach. In Squires, V.R., Sidahmed, A.E. (Eds.), Drylands: Sustainable Use of Range Lands into the Twenty-first Century (IFAD Series: Technical Report). pp. 97-106.

Galvin, K.A., 1992. Nutritional ecology of pastoralists in dry tropical Africa. American Journal of Human Biology 4, 209-221.

Galvin, K.A., 1994. Food choice during drought among Maasai women pastoralists of northern Tanzania. Invited Poster at the Session on Famine Foods: Food Choice Under Conditions of Scarcity at the annual meetings of the American Anthropological Association, Atlanta, 30 November-4 December.

Galvin, K.A., 1995. Conservation policy and human nutrition in Ngorongoro Conservation Area, Tanzania. Invited Paper Presented at the Session on Natural Resource Management in Eastern and Southern Africa: Issues of Sustainability and Conservation at the Annual Meetings of the Society for Applied Anthropology, Albuquerque, 29 March-2 April.

Galvin, K.A., 1997. Biological conservation and human nutrition by geographical location in the Ngorongoro Conservation Area, Tanzania. Poster Presented at the Human Biology Association Meetings, St Louis, 1-2 April.

Galvin, K.A., 1998. Compatibility of pastoralism and conservation? A test case using integrated assessment, in the Ngorongoro Conservation Area, Tanzania. Invited Paper Presented at the Session on Pastoralism at the International Congress of Anthropological and Ethnological Sciences, Williamsburg, VA, 27-31 July.

Galvin, K.A., Thornton, P.K., Mbogoh, S.G., 2000. Integrated Modeling and Assessment for Balancing Food Security, Conservation and Ecosystem Integrity in East Africa (Final Report to the GL-CRSP, Socio-Economic Modelling Component, 1997-2000). ILRI, Nairobi, Kenya.

Galvin, K.A., Ellis, J.E., McCabe, J.T., Moehlman, P., 1994. Wealth and nutrition among Maasai pastoralists in a conservation area, Tanzania (Poster presented at the annual meetings of the American Association of Physical Anthropologists, Denver, April). American Journal of Physical Anthropology 18 (Supplement), 91-92. (Abstract).

Galvin, K.A., Magennis, A., Ellis, J.E., Lynn, S., Smith N., 1999. Effects of conservation policy on human well-being: a comparative study of pastoral Maasai nutrition and economy in Northern Tanzania. Poster Presented at the Annual Meetings of the Human Biology Association, Columbus, OH, April.

Galvin, K.A., Ellis, J., Boone, R.B., Magennis, A.L., Smith, N.M., Lynn, S.J., Thornton, P.K., 2001. Compatibility of pastoralism and conservation? A test case using integrated assessment in the Ngorongoro Conservation Area, Tanzania. In: Chatty, D., Colester, M. (Eds.), Displacement, Forced Settlement and Conservation. Berghahn, Oxford. (in press).

Homewood, K.M., 1992. Development and the ecology of Maasai pastoralist food and nutrition. Ecology of Food and Nutrition 29, 61-80.

Homewood, K.M., Rodgers, W.A., 1991. Maasailand Ecology: Pastoralist Development and Wildlife Conservation in Ngorongoro, Tanzania. Cambridge University Press, Cambridge, UK.

Homewood, K.M., Rodgers, W.A., Arhem, K., 1987. Ecology of pastoralism in Ngorongro Conservation Area, Tanzania. Journal of Agricultural Science 108, 47-72.

Howe, R., Boone, R., DeMartini, J., McCabe, T., Coughenour, M., 1999. A Spatially Integrated Disease Risk Assessment Model for Wildlife/Livestock Interactions in the Ngorongoro Conservation Area of Tanzania. NREL, Fort Collins, CO.

Jones, P.G., Thornton, P.K., 1999. Application of a simple agricultural land-use model to the studying of market dynamics and technological change in a landscape in the Colombian Andes. Proceedings of the Third International Symposium on Systems Approaches for Agricultural Development (SAAD-3), 8-10 November 1999, Lima, Peru. ICASA-CIP-UNALM (2001) Centro Internacional del la Papa (CIP), Lima, Peru.

Kijazi, A., Mkumbo, S., Thompson, D.M., 1997. Human and livestock population trends. In: Thompson, D.M. (Ed.), Multiple Land-Use: The Experience of the Ngorongoro Conservation Area, Tanzania. IUCN, Gland, Switzerland, pp. 167-180. 
Lahey, 1997. Lahey Fortran 90 Language Reference and User Guide. LF90 v. 4.0. Lahey Computer Systems, Inc., NV.

Lynn, S., 2000. Conservation policy and local ecology: effects on Maasai land-use patterns and human welfare in northern Tanzania. MS thesis, Department of Range and Ecosystem Science, Colorado State University, Fort Collins, CO.

Magennis, A.L., Galvin. K.A., 2000. Growth patterns among Maasai pastoralists in northern Tanzania. Poster Presented at the Human Biology Association Meetings, April.

McCabe, J.T., Mollel, N., Tumaini, A., 1997a. Food security and the role of cultivation. In: Thompson, D.M. (Ed.), Multiple Land-Use: The Experience of the Ngorongoro Conservation Area, Tanzania. IUCN, Gland, Switzerland, pp. 397-416.

McCabe, J.T., Schofield, E.C., Nygaard Pedersen, G., Lekule, A., Tumaini, A., 1997b. Food security and nutritional status. In: Thompson, D.M. (Ed.), Multiple Land-Use: The Experience of the Ngorongoro Conservation Area, Tanzania. IUCN, Gland, Switzerland, pp. 285-302.

Moehlman, P.D., Runyoro, V.A., Hofer, H., 1997. Wildlife population trends in the Ngorongoro Crater. In: Thompson, D.M. (Ed.), Multiple Land-Use: The Experience of the Ngorongoro Conservation Area, Tanzania. IUCN, Gland, Switzerland, pp. 59-69.

NCAA (Ngorongoro Conservation Area Authority), 1999. 1998 Aerial Boma Count, 1999 People and Livestock Census, and Human Population Trend Between 1954 and 1999 in the NCA. Research and Planning Unit, Ngorongoro Crater, Tanzania.

Nestel, P., 1985. Nutritional status of Maasai women and children in relation to subsistence food production. PhD thesis, Queen Elizabeth College, University of London, London, UK.

Potkanski, T., 1997. Pastoral Economy, Property Rights and Traditional Nutual Assistance Mechanisms Among the Ngorongoro and Salei Maasai of Tanzania (Pastoral Land Tenure Series Monograph 2). IIED, London.

Reid, R.S., Thornton, P.K., Kruska, R.L., 2001. Livestock disease control and the changing landscapes of south-west Ethiopia. In: Angelsen, A., Kaimowitz, D. (Eds.), Agricultural Technologies and Tropical Deforestation. CAB International, Wallingford, UK, pp. 271-290.

Ritchie, J.T., 1998. Soil water balance and plant water stress. In: Tsuji, G.Y. et al. (Eds.), Understanding Options for Agricultural Production. Kluwer Academic Publishers, Dordrecht, pp. 41-54.

Smith, N.M., 1999. Maasai household economy: a comparison between the Loliondo Game Controlled Area and the Ngorongoro Conservation Area, northern Tanzania. MA thesis, Department of Anthropology, Colorado State University, Fort Collins, CO, USA.

Thompson, D.M. (Ed.), 1997. Multiple Land-Use: The Experience of the Ngorongoro Conservation Area, Tanzania. IUCN, Gland, Switzerland.

Thornton, P.K., Jones, P.G., 1997. Towards a conceptual dynamic land use model. In: Teng, P.S., Kropff, M.J., ten Berge, H.F.M., Dent, J.B., Lansigan, F.P., van Laar, H.H. (Eds.), Applications of Systems Approaches at the Farm and Regional Levels, Vol. 1. Kluwer Academic Publishers, Dordrecht, The Netherlands, pp. 341-356.

Thornton, P.K., Jones, P.G., 1998. A conceptual approach to dynamic land-use modelling. Agricultural Systems 57 (4), 505-521. 